\title{
Translation and validation of the Nepalese version of oral health impact profile(OHIP-14) questionnaire
}

\author{
Mannu Vikram ${ }^{1}$ and Varun Pratap Singh ${ }^{2^{*}}$ \\ *Correspondence: varundc@gmail.com \\ CrossMark \\ $\leftarrow$ Click for updates \\ 'Department of Conservative Dentistry and Endodontics, B.P.Koirala Institute of Health Sciences, Dharan, Nepal. \\ ${ }^{2}$ Department of Orthodontics and Dentofacial Orthopaedics, B.P.Koirala Institute of Health Sciences, Dharan, Nepal.
}

\begin{abstract}
Objective: The aim of this study was to develop a reliable and valid Nepali version of Oral Health Impact Profile (OHIP) Questionnaire.

Methods: The study was carried out at B.P. Koirala Institute of Health Sciences, Dharan, Nepal, a tertiary care health centre in Eastern Nepal. It was a cross-sectional questionnaire based survey. The English version of the OHIP-14 was translated in to Nepali, then back translation was done and pre-tested and subsequently self-administered to the subjects. The data was entered into Microsoft Excel 2007 and converted into Statistical Package for Social Science version 20 (SPSS v.20) which was used for statistical analysis. Internal consisitency was the main guiding factor for reliability and was measured using Cronbach's alpha. Construct validity was tested by factorial analysis.

$\underline{\text { Results: }}$ Cronbach's alpha of the translated scale was $>0.8$. Corrected item-total correlation coefficients ranged from $0.22-0.65$. Factorial analysis and the significant association between OHIP scores and the DMFT supports the construct validity of the instrument.

Conclusion: The translated version of the OHIP-14 questionnaire is a reliable and valid instrument to measure the oral health related quality of life (OHRQoL) in Nepalese adult population.
\end{abstract}

Keywords: Reliability, validity, OHIP-14, correlation coefficient

\section{Introduction}

Any disease or deformity affects an individual's health and oral diseases are no exception to this rule. The burden of sickness and suffering in an individual's life due to various oral diseases cannot be measured merely by clinical and epidemiological methods. It is the experience of that person which ultimately tells us about how that particular disease or ailment has actually affected his day to day life or quality of life [1]. Quality of life is defined by the World Health Organization as an individual's perceptions of his or her position in life in the context of the culture and value systems in which the individual lives and in relation to that individual's goals, expectations, standards, and concerns [2].

Oral health-related quality of life (OHRQoL) is considered as an important outcome of dental care. To measure OHRQoL especially in population-based studies, the Oral Health Impact Profile (OHIP) has been formulated [3]. The OHIP is a questionnaire with established validity and reliability and has been used in a wide range of OHRQoL studies [4]. The OHIP instrument has become very popular means to detect effectiveness of oral health care methods both in the clinical as well as research settings [5]. Due to the length of the original instrument, it became quite impractical to administer it and therefore a shorter version of 14 questions was formulated (OHIP14) and subsequently the validity and reliability when checked was found to be as reliable as the original questionnaire [6].
As the OHIP-14 was developed in English, it became difficult to administer these questionnaire in non-English speaking nations and in places where the local dialect was different from English. As a consequence of this, this instrument was translated into different languages like Brazilian [7], Mandarin [8], Taiwanese [9], Sinhalese [10] and many others as pertaining to the different geographical areas. Their psychometric properties were checked and subsequently those questionnaire have been used to assess the oral health related quality of life in those population.

Therefore, the aim of the present study was to test the psychometric properties of the translated Nepali version of the OHIP-14 instrument in terms of reliability and validity. This study holds importance in the fact that, as yet, no Nepalese version of the OHIP-14 is available and this instrument could be imperative to measure the oral health related quality of life in the Nepalese population.

\section{Methods}

Prior to beginning the study, an ethical clearance was obtained from Institutional Ethics Committee of B.P.Koirala Institute of Health Sciences, Dharan, Nepal which is a tertiary health care center with tertiary dental hospital as well. An initial translation of the original OHIP-14 was done into Nepali by a person who was proficient in both English as well as Nepali languages. The instrument was then back translated by a professional translator. 
Vikram et al. Oral Biology and Dentistry 2014,

http://www.hoajonline.com/journals/pdf/2053-5775-2-3.pdf

doi: $10.7243 / 2053-5775-2-3$

This was again translated into Nepali and a pretesting was done in about 25 individuals and necessary changes were done.

The OHIP-14 consists of a set of 14 questions measuring the functional limitation, physical pain, psychological discomfort, physical disability, psychological disability, social disability and handicap of persons that could arise as a result of problems with their teeth, mouth or dentures. The data for the present paper was obtained as part of the study to assess the oral health related quality of life in adult patients who were above 18 years of age and attended the outpatient department of a tertiary care hospital of Eastern Nepal. The responses were noted on a five point Likert scale: $1=$ never, 2 =hardly ever, $3=$ occasionally, $4=$ fairly often and $5=$ very often.

Convenience sampling was done from patients visiting the outpatient department of a tertiary care hospital of Eastern Nepal. Using the Bonnet's formula, taking $95 \%$ as the confidence level and a sampling error of $5 \%$ and considering the Cronbach's alpha value of 0.8 as acceptable, the sample size was found to be 135 .

The questionnaire was designed to be self administered. This was done in a room in the department of Conservative Dentistry and Endodontics which was specially used for this purpose to maintain privacy and confidentiality of the patient. The socio-demographic data was also collected from each individual before administering the questionnaire. The Decayed Missing Filled Teeth (DMFT) was examined in each individual.

For the data analysis SPSS version 20 statistical package was used and reliability was measured in terms of internal consistency using Cronbach's alpha which asseses the overall correlation between items within a scale. Corrected item total correlation was also calculated for the different items in the OHIP-14 questionnaire. Construct validity and convergent validity was carried out by doing factor analysis and correlation between the DMFT score and OHIP score respectively.

\section{Results}

According to the data collected from the socio-demographic profile, $53 \%$ were males among the 135 respondents. Overall the level of education was below average and more than half the subjects had never studied the English language. Even those who had elementary knowledge of English had difficulty understanding the meaning of simple words.

The Cronbach's alpha was 0.83 which shows a good internal consistency of the instrument. (Table 1) shows the individual Cronbach's alpha when each item of the questionnaire is deleted. Also shown in the table is the corrected item total correlation for each item of the questionnaire.

Construct validity was obtained by doing factorial analysis of the scale. The principal component analysis with orthogonal rotation using the varimax procedure and Kaiser Normalization extracted 5 factors. The results of the factorial analysis are shown in (Table 2).

There was a high correlation between the examined oral health status and the DMFT scores (Table 3). The DMFT scores
Table 1. Showing Cronbach's alpha if items deleted for the 14 questions and also the corrected item total correlation.

\begin{tabular}{|c|c|c|c|}
\hline Component & Items & $\begin{array}{l}\text { Corrected } \\
\text { Item Total } \\
\text { Correlation }\end{array}$ & $\begin{array}{l}\text { Cronbach's } \\
\text { Alpha if } \\
\text { Item Deleted }\end{array}$ \\
\hline \multirow[t]{2}{*}{ Functional Limitation } & $\begin{array}{l}\text { Difficulty in } \\
\text { pronouncing } \\
\text { words }\end{array}$ & 0.479 & 0.825 \\
\hline & $\begin{array}{l}\text { Taste has } \\
\text { worsened }\end{array}$ & 0.303 & 0.831 \\
\hline \multirow[t]{2}{*}{ Physical Pain } & Pain in mouth & 0.617 & 0.811 \\
\hline & $\begin{array}{l}\text { Uncomfortable } \\
\text { eating food }\end{array}$ & 0.637 & 0.809 \\
\hline \multirow[t]{2}{*}{ Psychological Discomfort } & $\begin{array}{l}\text { Self- } \\
\text { consciousness }\end{array}$ & 0.464 & 0.827 \\
\hline & Tense feeling & 0.655 & 0.807 \\
\hline \multirow[t]{2}{*}{ Physical Disability } & $\begin{array}{l}\text { Unsatisfactory } \\
\text { diet }\end{array}$ & 0.565 & 0.815 \\
\hline & $\begin{array}{l}\text { Interruption of } \\
\text { meals }\end{array}$ & 0.548 & 0.817 \\
\hline \multirow[t]{2}{*}{ Psychological Disability } & $\begin{array}{l}\text { Difficult to } \\
\text { relax }\end{array}$ & 0.412 & 0.826 \\
\hline & $\begin{array}{l}\text { Feeling } \\
\text { embarrassed }\end{array}$ & 0.547 & 0.817 \\
\hline \multirow[t]{2}{*}{ Social Disability } & $\begin{array}{l}\text { Irritable with } \\
\text { others }\end{array}$ & 0.319 & 0.831 \\
\hline & $\begin{array}{l}\text { Difficulty } \\
\text { doing usual } \\
\text { jobs }\end{array}$ & 0.379 & 0.828 \\
\hline \multirow[t]{2}{*}{ Handicap } & $\begin{array}{l}\text { Life less } \\
\text { satisfying }\end{array}$ & 0.361 & 0.829 \\
\hline & $\begin{array}{l}\text { Totally unable } \\
\text { to function }\end{array}$ & 0.228 & 0.834 \\
\hline
\end{tabular}

for each individual was noted down and correlated with the OHIP-14 scores. It was seen that the OHIP-14 scores were higher for those individuals who had higher DMFT scores and vice-versa.

\section{Discussion}

A suitable instrument to measure the oral health related quality of life in the Nepalese population was needed since a very long time. Since, the English version of OHIP-14 would not have been locally effective to administer, hence a translation and validation of the existing OHIP-14 was carried out into Nepali language. Therefore, the present study has attempted to develop a suitable version of the OHIP-14 instrument and validate its psychometric properties. As far as the authors' knowledge and according to the literature search, no previous study exists in Nepali validating the OHIP-14 instrument and this is the first of its kind.

For any instrument to be effective, its reliability should be very high. The reliability for these instruments are generally measured in terms of Cronbach's alpha. In this case, we obtained a high Cronbach alpha value of 0.83 . According to 
Vikram et al. Oral Biology and Dentistry 2014,

Table 2. Principal factorial analysis with extracted components, salient loadings, eigenvalues and percentage of variance explained. Factor loadings $>0.3$ are highlighted in bold.

\begin{tabular}{l|lllll}
\hline \multirow{2}{*}{ Items } & \multicolumn{5}{l}{$\begin{array}{l}\text { Factor loadings of each component } \\
\text { derived }\end{array}$} \\
\cline { 2 - 6 } & $\mathbf{1}$ & $\mathbf{2}$ & $\mathbf{3}$ & $\mathbf{4}$ & $\mathbf{5}$ \\
\hline $\begin{array}{l}\text { Difficulty in pronouncing } \\
\text { words }\end{array}$ & $\mathbf{0 . 5 8 2}$ & $\mathbf{0 . 4 2 7}$ & -0.164 & -0.063 & -0.189 \\
Taste has worsened & $\mathbf{0 . 4 0 5}$ & $\mathbf{0 . 5 0 1}$ & -0.175 & -0.431 & -0.155 \\
Pain in mouth & $\mathbf{0 . 6 8 6}$ & -0.413 & 0.176 & -0.107 & 0.109 \\
Uncomfortable eating food & $\mathbf{0 . 7 1 6}$ & -0.249 & 0.108 & -0.180 & -0.378 \\
Self-consciousness & $\mathbf{0 . 5 5 7}$ & -0.245 & 0.282 & -0.312 & 0.108 \\
Tense feeling & $\mathbf{0 . 7 3 3}$ & -0.129 & -0.356 & -0.119 & 0.026 \\
Unsatisfactory diet & $\mathbf{0 . 6 7 2}$ & 0.075 & 0.039 & 0.025 & -0.223 \\
Interruption of meals & $\mathbf{0 . 6 5 0}$ & -0.117 & 0.248 & -0.047 & 0.094 \\
Difficult to relax & $\mathbf{0 . 5 0 8}$ & -0.148 & $\mathbf{0 . 5 1 0}$ & $\mathbf{0 . 5 7 0}$ & -0.108 \\
Feeling embarrassed & $\mathbf{0 . 6 3 4}$ & -0.267 & -0.410 & 0.165 & 0.182 \\
Irritable with others & $\mathbf{0 . 4 1 6}$ & $\mathbf{0 . 5 4 4}$ & 0.101 & $\mathbf{0 . 5 3 9}$ & 0.192 \\
Difficulty doing usual jobs & $\mathbf{0 . 4 8 4}$ & $\mathbf{0 . 5 7 0}$ & 0.165 & -0.017 & -0.133 \\
Life less satisfying & $\mathbf{0 . 4 5 0}$ & -0.124 & -0.648 & $\mathbf{0 . 3 3 6}$ & 0.146 \\
Totally unable to function & 0.285 & 0.230 & 0.188 & -0.257 & $\mathbf{0 . 8 2 5}$ \\
Eigen values & 4.560 & 1.540 & 1.290 & 1.160 & 1.000 \\
\% of variance explained & 32.51 & 11.03 & 9.220 & 8.350 & 7.700 \\
\hline & & & & & \\
\hline
\end{tabular}

Table 3. Correlation between the examined oral health status and the DMFT scores.

\begin{tabular}{lllll}
\hline Variable & Mean & $\begin{array}{l}\text { Standard } \\
\text { Deviation }\end{array}$ & $\begin{array}{l}\text { Correlation } \\
\text { Coefficient (Pearson) }\end{array}$ & p-Value \\
\hline OHIP-14 Scores & 23.45 & 7.73 & 0.952 & $0.000^{* *}$ \\
DMFT Scores & 5.90 & 2.06 & -- & -- \\
\hline
\end{tabular}

Nunnally and Bernstein, the standard criteria for reliability should have a minimum value of Cronbach's alpha as 0.7 [11]. The value of Cronbach's alpha did not rise more than 0.83 even when any of the 14 items were deleted from the instrument. This signifies that the consistency of the questions in the instrument had a good uniformity. Since the Cronbach's alpha value did not increase even after deleting individual items in the questionnaire, it shows the items were well fitted to the scale.

Another significant consideration for including any item in the scale is that the minimum corrected item-total correlation coefficient should be 0.20 . The corrected item total correlation coefficients in this case had a range from 0.228 to 0.655 which indicated a very satisfactory homogeneity and justified the inclusion of the items in the scale.

When subjected to principal component factor analysis with orthogonal rotation 5 factors were extracted, the 4 components have Initial Eigen values greater than 1, further the scree-plot confirmed the extraction of 5 components and they could explain $68.61 \%$ of the total variation. However when salient loadings were analyzed, all the items have significant salient factor loadings in component 1 except item 14 which may be attributed to conceptual differences among various populations.

There was a high correlation between the OHIP-14 scores and DMFT scores. Individuals in whom the DMFT scores were high had higher OHIP-14 scores and vice-versa. The Pearson's correlation coefficient was 0.953 signifying the high degree of correlation between OHIP-14 and the DMFT scores. This correlation therefore supports the construct validity of the instrument.

\section{Conclusion}

The translated version of the OHIP-14 questionnaire is a reliable and valid instrument to measure the oral health related quality of life (OHRQoL) in Nepalese adult population. Further studies on the oral health related quality of life in the Nepalese population may be carried out using this translated version of the OHIP instrument.

\section{Competing interests}

The authors declare that they have no competing interests.

Authors' contributions

\begin{tabular}{|l|c|c|}
\hline Authors' contributions & MV & VPS \\
\hline Research concept and design & $\checkmark$ & $\checkmark$ \\
\hline Collection and/or assembly of data & $\checkmark$ & -- \\
\hline Data analysis and interpretation & -- & $\checkmark$ \\
\hline Writing the article & $\checkmark$ & -- \\
\hline Critical revision of the article & -- & $\checkmark$ \\
\hline Final approval of article & $\checkmark$ & $\checkmark$ \\
\hline Statistical analysis & -- & $\checkmark$ \\
\hline
\end{tabular}

Acknowledgement

The authors would like to acknowlege Dr. Bhusan Bhattrai for his help in the initial translation process during the study.

\section{Publication history}

EIC: Thimios A. Mitsiadis, University of Zurich, Switzerland.

Received: 18-Dec-2013 Revised: 26-Jan-2014

Accepted: 07-Feb-2014 Published: 25-Feb-2014

\section{References}

1. Slade GD. Oral health-related quality of life is important for patients, but what about populations? Community Dent Oral Epidemiol. 2012; 40 Suppl 2:39-43. | Article | PubMed Abstract I PubMed Full Text

2. Harper A. World Health Organization, Programme on Mental Health: WHOQOL-BREF: Introduction, administration, scoring and generic version of the assessment. Geneva, World Health Organization, 1996. I Pdf

3. Wolfart S, Moll D, Hilgers RD, Wolfart M and Kern M. Implant placement under existing removable dental prostheses and its effect on oral health-related quality of life. Clin Oral Implants Res. 2013; 24:1354-9. I Article | PubMed

4. Slade GD and Spencer AJ. Development and evaluation of the Oral Health Impact Profile. Community Dent Health. 1994; 11:3-11. | PubMed

5. Masood M, Masood Y, Saub R and Newton JT. Need of minimal impor- 
Vikram et al. Oral Biology and Dentistry 2014,

http://www.hoajonline.com/journals/pdf/2053-5775-2-3.pdf

tant difference for oral health-related quality of life measures. J Public Health Dent. 2012. | Article | PubMed

6. Slade GD. Derivation and validation of a short-form oral health impact profile. Community Dent Oral Epidemiol. 1997; 25:284-90. | Article | PubMed

7. Oliveira BH and Nadanovsky P. Psychometric properties of the Brazilian version of the Oral Health Impact Profile-short form. Community Dent Oral Epidemiol. 2005; 33:307-14. | Article | PubMed

8. Liu JY, Pow EH, Chen ZF, Zheng J, Zhang XC and Chen J. The Mandarin Chinese shortened version of Oral Health Impact Profile for partially edentate patients with implant-supported prostheses. J Oral Rehabil. 2012; 39:591-9. | Article | PubMed

9. Kuo HC, Chen JH, Wu JH, Chou TM and Yang YH. Application of the Oral Health Impact Profile (OHIP) among Taiwanese elderly. Qual Life Res. 2011; 20:1707-13. | Article | PubMed

10. Ekanayake $L$ and Perera I. Validation of a Sinhalese translation of the Oral Health Impact Profile-14 for use with older adults. Gerodontology 2003; 20:95-9. | Article | PubMed

11. Nunnally J C and Bernstein I. PsychometricTheory. 2nd ed. New York, USA: McGraw-Hill, 1994. | Book

\section{Citation:}

Vikram $\mathrm{M}$ and Singh VP. Translation and validation of the Nepalese version of oral health impact profile(OHIP-14) questionnaire. Oral Biol Dent. 2014; 2:3.

http://dx.doi.org/10.7243/2053-5775-2-3 